Takhtameshlou, S.R., Abbasalizadeh, A.R., Ashtiani, H.V., Shafaghi, S., Ghorbani, F., Ansari, N.,

Ghasemalipour, M., Shafaghi, S.

IMPACT OF USING INNOVATION ON BUSINESSES DURING THE COVID-19 PANDEMIC

\title{
IMPACT OF USING INNOVATION ON BUSINESSES DURING THE COVID-19 PANDEMIC
}

\author{
Soheila Roshani Takhtameshlou \\ Industrial Management, Islamic Azad University, Central Tehran Branch, Tehran, Iran \\ Inv.soheilaroshani@gmail.com
}

\section{Alireza Rastegar Abbasalizadeh}

President of International Federation of Inventors' Associations, Geneva, Switzerland president@ifia.com

\section{Hossein Vaezi Ashtiani}

Executive Committee Member, International Federation of Inventors' Associations, Geneva,

Switzerland

vaezi_58@yahoo.com

Shadi Shafaghi

Lung Transplantation Research Center, National Research Institute of Tuberculosis and Lung

Diseases (NRITLD), Shahid Beheshti University of Medical Sciences, Tehran, Iran

Shafaghishadi@yahoo.com

\section{Fariba Ghorbani}

Tracheal Diseases Research Center, National Research Institute of Tuberculosis and Lung

Diseases(NRITLD), Shahid Beheshti University of Medical Sciences, Tehran, Iran

Dr.f.ghorbani@gmail.com

\section{Niusha Ansari}

Department of Medical Sciences \& Technologies, Science and Research Branch, Islamic Azad

University, Tehran, Iran

niusha.ansari@gmail.com

\section{Mehdi Ghasemalipour}

Industrial engineering, University of Tehran, Fouman Faculty of Engineering, Guilan, Iran mehdighasemalipour@gmail.com

Masoud Shafaghi

Strategic Planning and Executive Office Manager, International Federation of Inventors' Associations, Geneva, Switzerland

Masoud.shafaghi@ifia.com 


\title{
Takhtameshlou, S.R., Abbasalizadeh, A.R., Ashtiani, H.V., Shafaghi, S., Ghorbani, F., Ansari, N., \\ Ghasemalipour, M., Shafaghi, S.
}

IMPACT OF USING INNOVATION ON BUSINESSES DURING THE COVID-19 PANDEMIC

\section{Abstract}

A platform has been created by Innovation in which businesses have chosen activism and functionalism against being influential and actionable and they turn any threat into an opportunity by employing an innovative approach. Since 2019 when the Covid-19 pandemic appeared, besides the contagious effect, it has influenced worldwide business in different aspects. It might be interesting that most of the industries and companies are willing to continue their businesses even after the pandemic with half of their capacity and teleworking. An epidemic of a disease or a virus is not a new crisis and over time, developed and underdeveloped countries have faced this crisis, but some manufacturers and owners have taken advantage of innovation to turn threats into opportunities in business settings to create profitability and promote market development of their products and services. During the Covid-19 pandemic, the need to take advantage of innovation for stability, durability, and sustainability of businesses is felt more than ever. In this article, we investigated economic and social policymaking at public levels compared to the use of innovations and their consequences. Overtaking business competitors, spreading the culture of innovation, creating new job opportunities, turning threats into opportunities, long-term survival of businesses, and creating competitive advantages encourage business owners to make more use of innovation in businesses during and after the Covid-19 pandemic.
\end{abstract}

Keywords: Innovation, Covid-19, Small business, Business report, Management

DOI: https://doi.org/10.24818/beman/2021.S.I.2-12

\section{INTRODUCTION}

SARS-Cov2-19 or the crisis virus is the biggest challenge against the world after World War II. According to The United Nations Development Programme (UNDP), the economic shocks created by this virus are much greater than the health shocks and even after the return of health to the world, the economic crisis may remain for years (Board et al., 2021). According to published reports, it has been emphasized that the virus causes destructive social, economic, and political consequences (Alzúa \& Gosis, 2020). In economic zones, it is witnessed that a lot of people lose their jobs and incomes every day and they do not know when conditions are normal or will be normal. The coronavirus appeared in Wuhan, China, in 2019 and led to a pandemic followed by destructive effects on a wide range of economic, social, and political dimensions. Many small businesses have been affected by this pandemic. However, on a large scale, large businesses and manufacturing and service industries around the world operate at only half of their capacity.

At the same time, the coronavirus outbreak has led to serious damages to businesses at national and international levels and due to its complexity as well as high transmission rate, it is very difficult to present a particular model to maintain and protect businesses quickly. Small businesses provide jobs and economic growth for national economy. For example, small countries that are islands and are highly dependent on the tourism industry are faced with deserted restaurants and beaches. In other countries, micro businesses such as shops, restaurants, and fitness clubs are closed and many macro businesses are working at half capacity (Bartik et al., 2020) (predicting changes in revenue from the tourism industry due to the spread of the coronavirus from 2019 to 2020). The International Labour Organization (ILO) estimates that 40 million jobs will be lost (International Labour Organization, 2020) and the World Bank 
predicts that remittances have dropped by 110 billion dollars this year that means 800 million people cannot meet their basic needs ("COVID-19 Cris. Through a Migr. Lens," 2020). At the international level, large industrial countries such as the United States, Germany, England, France, and Italy that have always been at the forefront of GDP are severely suffering from the Covid-19 crisis and according to the International Monetary Fund (IMF), negative growth is predicted and it is expected that 172 countries will experience negative growth (Jackson et al., 2020). According to world GDP evolution statics, we had a sharp downward in early 2020 and this GDP decrease is the result of the pandemic.

Moreover, economists predict that the GDP level will not return to the level before the Covid-19 crisis by 2023 and countries with low and medium development will suffer most, not only economically, but also socially and politically and people living in these countries will be on the verge of this loss (Walmsley et al., 2020)(Walmsley et al., 2020). The Organization for Economic Cooperation and Development (OECD) showed that it has lowered its expectations for global growth and warned that the growth rate will drop from $2.9 \%$ to $2.4 \%$ and even to $1.5 \%$ (Singh \& Singh, 2020).

In other view, the coronavirus has caused reversed human growth for the first time in 30 years. According to the World Food Programme, in 2020, about 100 million people were exposed to extreme poverty while 270 million people are at a risk of acute food insecurity (International Labour Organization, 2020)(Europe, 2017)(Economy, 2020). On the other hand, factories, industries, and manufacturing companies are working with lost working hours and their minimum capacity. According to ILO statistics, the number of working hours lost in the first half of 2020 was significantly higher than estimations while the very uncertain recovery in the second half of the year will not be enough to return to pre-epidemic levels and the risk of extinction threatens large businesses. For example, at regional level, lost working hours consist of the United States (18.3\%), Europe and Central Asia (13.9\%), Asia and Pacific Ocean (13.5\%), Arabic countries (2.13\%), and Africa (12.1\%) and a vast majority of the world's workers (93\%) continue to live in countries with a kind of closed workplace that most of these restrictions have been in the Americas (Europe, 2017). Moreover, according to ILO, it is expected that the Covid-19 crisis will destroy $-6.7 \%$ of working hours; financially, about 195 million full-time workers in the second quarter of 2020. In Asia and Pacific Ocean, it will account for 7.2\% (125 million full-time workers). ILO estimates that 13 million people will lose their jobs (Verma \& Prakash, 2020).

In this respect, it is very difficult to have access to accurate information from manufacturers and consumers who play an important role in the development of businesses. Manufacturers do not know how much products should be produced to meet market consumption and retailers, on the other hand, are worried about local markets and urban quarantine policies and their impacts on the demands of their customers. Lack of customer presence and sufficient information from the customer has a large impact 


\section{Takhtameshlou, S.R., Abbasalizadeh, A.R., Ashtiani, H.V., Shafaghi, S., Ghorbani, F., Ansari, N., Ghasemalipour, M., Shafaghi, S.}

IMPACT OF USING INNOVATION ON BUSINESSES DURING THE COVID-19 PANDEMIC

on upstream and downstream businesses. Upstream companies that supply raw materials needed by businesses, will not be able to produce and supply when production activities are stopped and indeed, they will lose their market and downstream businesses that are mainly retailers and end sale points, will lose end customers who refuse to buy due to strict limitations and social distancing.

In the meanwhile, innovation is turning to activism (as opposed to being passive) that is a feature of this approach relative to conventional processes. The use of innovation identifies every opportunity quickly and takes advantage of it with creativity. In this approach, customers and suppliers are considered as an inspirational source for product design and innovative idea against threats.

Although businesses have always been influenced by various events and crises such as volcanic eruptions, tsunamis, floods, and hurricanes, still many occupations are not ready to face future crises. The interesting point is that different communities have faced different epidemics such as Ebola virus in 2014 and SARS and MERS in 2012 which spread in the Middle East (Verma \& Prakash, 2020) and had considerable effects on businesses at regional and international levels.

\section{MATERIALS AND METHODS}

In this study, through investigating different scenarios and sources, economic and social policymaking during the Covid-19 pandemic were studied and three general strategies were pointed out that industry and business owners can use their innovation and technology to protect themselves against this crisis. In 2020, ILO suggested three models according to the considered approaches that can be used to improve conditions:

> The basic model: predicted the return of economic activities according to time forecasts, elimination of restriction in the workplace, and recovery of consumption and investments $(4.9 \%$ of work equivalent to 140 million full-time jobs in the fourth quarter of 2019) (Europe, 2017) .

$>$ Pessimistic scenario: the second wave of epidemics led to the return of restrictions. As a result, working hours reduced by $11.9 \%$, equivalent to 340 million full-time jobs (ILO-OECD, 2020).

$>$ Optimistic scenario: it has assumed that workers' activities will resume quickly and total demands and job creation will be improved considerably. With this wonderful improvement program, lost working hours (1.2\% and 34 million full-time jobs) reduce quickly (International Monetary Fund, 2020). As it seems, employment of these policies at the general level has not solved the problems of people during the crisis and every day, we see more strict strategies at a general level of the society and livelihood problems and lost working hours and economic recession at national and international levels. But what about the business area with the presence of innovation? How is it possible to use 
innovation and change consumption habits and achieve profitability during this crisis? We have investigated this approach from three aspects.

\subsection{Innovation in industry}

Development (slow and steady) of innovation is not something that can be done quickly. Indeed, to be successful in businesses and taking advantage of innovation, long-term strategies and flexible programs with a forward-looking vision should be employed that will flourish in the future. This is the way that large companies such as Amazon and Lighthouse are following. Owners of these innovative companies welcome new and innovative ideas and allow their staff to express their creative thoughts and have become leaders in innovation and technology. In the meanwhile, the most important aspect for the managers and owners of industries and occupations is creating and welcoming innovation in all business areas. According to Covid-19 brief note report (Practice, 2021) the growth rate is indicated and noted as a positive number despite the corona pandemic situation. With the epidemic that influenced $93 \%$ of companies around the world during the Covid-19 crisis, Lighthouse achieved higher production and new revenue streams (Betti \& Boer, 2020).

\subsection{Short-term policymaking (creating new consumption habits)}

Successful introduction of a new innovative product to the market is a big challenge for business owners in the highly competitive market and those are successful who have innovative thoughts and employ a variety of methods. Since the consumer determines the success or failure of a new innovative product, business owners should meet their needs and identify the difference between themselves and other competitors to let the customer choose the innovative product easily and take advantage of its benefits. It should be noted that many consumers are not easily receptive to change and are often hesitant to use a new product. People create habit chain but most of these consumers do not want to change old habits and cannot accept new things; therefore, the use of creativity and innovation in production is an effective step to be successful in the market. Companies such as Amazon that have employed innovation and creativity, influence people's habits with intelligent moves and encourage consumers to try a new product and replace the old one. At this time, allocation of training hours and employment of user-friendly applications and software have helped this company to take a lead in providing services and products and created a new pattern of behavior in consumers. Big changes often result from small progresses over time. Consumer behavior change is the same. Many trial programs are performed at small and regional scales that led to a steady growth and continued profitability of Amazon. This company, before 
the products enter the market, analyzes feedbacks from target consumers and then supplies them and this is when the new product creates its market.

\subsection{Long-term and strategic policymaking (internet of things - the use of artificial intelligence and robot technology)}

Centralized growth, market development in line with customer needs, product development, homogeneous and heterogeneous diversity, changing consumer habits, joint venture, and strategic alliance are among long-term and strategic planning that are developed to benefit from innovation as much as possible. It cannot be denied that the created crisis in business environment has created different patterns in consumption, purchase, and supply. Internet of Things (IOT), artificial intelligence, and technology have facilitated access and enjoyment of services and products even with urban quarantine restrictions. A different product of Amazon was designed and released in this regard. Amazon started piloting Scout in Washington since January. This electric device is an electric robot that is connected to six wheels and a load compartment and is considered for short distances. Prime shipment drones were designed in line with Amazon's long-term plans. This service was tested for the first time in 2016 in rural areas of England and accordingly, Amazon introduced new automatic drones that can handle loads weighting 5 pounds and 15 miles high.

\section{DISCUSSION}

Innovation interventions have been effective to deal with the Covid-19 crisis and huge investments have been made in the field of the fourth industrial revolution. By using the right available tools and smart implementation of innovation, we can guarantee the survival of businesses to some extent. In various fields, managers and experts believe that innovation is the solution for future crises. In businesses, for new value creation, producing and supplying a product or services, creating new job opportunities, and achieving profit and maintain profitability, innovation and creativity should be taken into consideration that this approach suffers from limitations.

\subsection{Industry and rejection of innovation}

In recent years that the internet use is very pervasive and web-based businesses are formed, the use of innovation and creativity terms is increased. In this situation, managers and experts sometimes say if we have problem in creating new jobs, the reason is that we do not have creative ideas and the main question is that what is the barrier against implementing innovative thoughts? We investigated this issue from two aspects. 
Innovation has little demand!!! Or the risk of using innovation is high!!! Innovative products enter the market to meet a need. These products include physical products, services, experiences, information, and new ideas and the final objective of presenting these products is replacing innovative ideas to facilitate the use of equipment and tools, create a competitive advantage, market development, and value creation and profitability. Product innovation in terms of Oslo Guidelines means "introduction of products or services that are new or with significant improvements in terms of properties or conscious applications." This innovation includes improvements in technical properties, components, ingredients, connected software, ease of use, and other functional properties (Oslo Guidelines, 2005((Collecting \& Data, 2005))) (Kogabayev \& Maziliauskas, 2017).

Different industries are producing and supplying innovative and creative products that sometimes experience failure or are not welcomed by the general industry and end consumers. Although before introducing the product, all marketing issues such as market assessment, creating new markets, advertisements, and sales are taken into consideration, the problem is that why market and end consumers in some cases show passive reaction or reject the product? Rodgers and Shomicker (1995) introduce relative advantage, compatibility, simplicity, ease of use, free trial, and visibility as the most important properties that affect innovation acceptance. Relative advantage points to the superiority of current innovation over past innovations. They believe that relative advantage shows the intensity of profits and losses due to innovation acceptance. It should be noted that factors affecting relative advantage do not follow a specific law. In fact, what creates relative advantage includes needs and perceptions of the user community. Compatibility is another factor that affects innovation acceptance. Compatibility means coordinating innovation with people's values, activities, and needs. Innovation that is not compatible with values, experiences, needs, and social norms will be rejected by the community (Rogers et al., 2005). Yee et al. (2006) believe that simplicity, ease of use, and the degree of difficulty of using an innovation have a great impact on innovation acceptance (Yi et al., 2006).

\subsection{Technology and lack of confidence and suitable infrastructures}

According to the Webster Dictionary, technology is defined as a branch of knowledge that deals with applied, engineering, industrial, and art knowledge or uses knowledge for a practical outcome (Cennamo et al., 2000). It should be noted that the use of technology during the Corona pandemic is increased significantly. For this reason, to use technology, experts in the fields of cloud computing, IOT, and cyber security should be trained.

The major challenge against using these technologies is lack of sufficient security for the environment of these systems. For example, public access, vulnerability to hackers, not spending enough time to secure 
against security holes and hacker intrusion, lack of necessary knowledge required by companies and manufacturing industries for security due to rapid growth of the use of these tools, and lack of a suitable platform for additional security for applications and software are among the main concerns of technology users.

With IOT development, countless devices are connected to the internet every day and the biggest challenge in this regard is providing security for these devices. It was predicted that by 2020 , about 24 billion devices from jet turbines to cameras and cars across the globe will be connected to the internet that this issue shows the importance of IOT security more than ever.

Cloud processing and terms with their benefits and effects on organizational agility and low costs cause problems. Small and large organizations and companies and even startups are becoming increasingly aware of the value of cloud computing and the benefits they can obtain and take steps towards using this technology more than ever.

Some groups spend a lot of money to set private cloud for their organizations and provide internal services on private clouds or provide services through public cloud and other groups become the customers of these services and transfer a part of their commercial services to these clouds that the main challenge of cloud computing is the security model in meeting security needs and eliminating legal ownership concerns related to organizational and commercial information and data in online and multimodal cloud environments.

Smooth and easy transition of businesses towards innovation and technology necessitates a full understanding of benefits and opportunities as well as identifying the challenges and problems associated with technology and innovation. What is highly important is the degree of interaction, how to use, and ease of use of these innovations and technologies.

\section{CONCLUSION}

The purpose of this study was to find out how innovation affects businesses during and after the pandemic.

The advantages of using innovation in business can be as follows:

- Differentiate businesses from competitors

- Longer life of companies and businesses

- Provide strategic goods and vital services continuously with a considerable speed

- Provide new platforms and different opportunities for businesses

- Progress towards the fourth and fifth industrial revolutions and scaping from a world without technology 
- Create new job and job opportunities for company employees even with the mechanization and use of artificial intelligence

- Create a futuristic and research-oriented outlook for business owners

- Spread the culture of using innovation after the Corona pandemic

- Encourage traditional business owners and replace them with innovative and modern businesses

- Create a suitable platform by governments for businesses and business owners, expanding and promoting it

Although innovation introduces countless benefits, there are some disadvantages such as mental frameworks of users, the constraints imposed by governments, lack of awareness and unfamiliarity with innovation for older people, and lack of access to innovation in developing and less developed countries which must be taken into consideration.

Despite the fact that the Covid-19 pandemic is a crisis around the world, it trains all businesses, both traditional and modern, to use their innovation to expand their business beyond the scope of thought.

\section{REFERENCES}

Alzúa, M. L., \& Gosis, P. (2020). Social and economic impact of Covid-19 and policy options in Argentina. Undp Lac C, 10.

Bartik, A. W., Bertrand, M., Cullen, Z., Glaeser, E. L., Luca, M., \& Stanton, C. (2020). The impact of COVID-19 on small business outcomes and expectations. Proceedings of the National Academy of Sciences of the United States of America, 117(30), 17656-17666. https://doi.org/10.1073/pnas.2006991117

Betti, F., \& Boer, E. de. (2020). Global Lighthouse Network: Four Durable Shifts for a Great Reset in Manufacturing. WWE \& Mckinsey, September, 14-15.

Board, T. E., Coordinators, R., Islands, M., Kitts, S., \& Islands, S. (2021). Update on UNDP' 's Socio economic Response Beyond Recovery: Towards 2030 Fast and Furious : COVID-19 Impact on Countries. 2024(May), 1-23.

Cennamo, A., Falsetto, A., Gallo, G., Lanna, M., Calleri, G., \& Di Giacomo, D. (2000). Warthin's tumour in the parotid gland (an inflammatory or a neoplastic disease?). Chirurgia Italiana, 52(4), 361-367.

Collecting, G. F. O. R., \& Data, I. I. (2005). Third edition ORGANISATION FOR ECONOMIC COOPERATION. In Communities: Vol. Third edit.

COVID-19 Crisis Through a Migration Lens. (2020). COVID-19 Crisis Through a Migration Lens, April. https://doi.org/10.1596/33634

Economy, T. G. (2020). Global Outlook: Pandemic, Recession: The Global Economy in Crisis. 1-66. https://doi.org/10.1596/978-1-4648-1553-9_ch1

Europe, S. (2017). Labour market developments. 1-35. https://doi.org/10.1787/eco_surveys-nzl-2017graph8-en

ILO-OECD. (2020). The impact of the COVID-19 pandemic on jobs and incomes in G20 economies. 46.

International Labour Organization. (2020). COVID-19 and the world of work: Updated estimates and analysis. ILO Monitor, 1-22.

International Monetary Fund. (2020). Mitigating Climate Change-Growth- and Distribution-Friendly 
Takhtameshlou, S.R., Abbasalizadeh, A.R., Ashtiani, H.V., Shafaghi, S., Ghorbani, F., Ansari, N.,

Ghasemalipour, M., Shafaghi, S.

IMPACT OF USING INNOVATION ON BUSINESSES DURING THE COVID-19 PANDEMIC

Strategies. In World Economic Outlook: A Long and Difficult Ascent.

Jackson, J., Weiss, M., Schwarzenberg, A., \& Nelson, R. (2020). Global Economic Effects of COVID-19. Congressional Research Service, 20, 78.

Kogabayev, T., \& Maziliauskas, A. (2017). The definition and classification of innovation. HOLISTICA Journal of Business and Public Administration, 8(1), 59-72. https://doi.org/10.1515/hjbpa-20170005

Practice, R. (2021). COVID-19 : Briefing note. August.

Rogers, E. M., Medina, U. E., Rivera, M. a, \& Wiley, C. J. (2005). Complex Adaptive Systems and The Diffusion of Innovations. The Innovation Journal: The Public Sector Innovation Journal, 10(3), 126.

Singh, J., \& Singh, J. (2020). D. COVID Impact on Society. Electronic Research Journal of Social Sciences and Humanities, 2(I), 168-172.

Verma, A. K., \& Prakash, S. (2020). Impact of COVID-19 on environment and society. Journal of Global Biosciences, 9(5), 7352-7363.

Walmsley, T., Rose, A., \& Wei, D. (2020). The Impacts of the Coronavirus on the Economy of the United States. In SSRN Electronic Journal. Economics of Disasters and Climate Change. https://doi.org/10.2139/ssrn.3678835

Yi, M. Y., Jackson, J. D., Park, J. S., \& Probst, J. C. (2006). Understanding information technology acceptance by individual professionals: Toward an integrative view. Information and Management, 43(3), 350-363. https://doi.org/10.1016/j.im.2005.08.006 